\title{
An Investigation of the Psychometric Properties of Emotional Intelligence Scale Using Item Response Theory
}

\author{
Said Aldhafri ${ }^{1,2,{ }^{*}}$ \& Yousef Abu Shindi ${ }^{1}$ \\ ${ }^{1}$ Department of Psychology, College of Education, Sultan Qaboos University, Oman \\ ${ }^{2}$ Director of Social Observatory Research Program, TRC. \\ *Correspondence: Muscat, P.O.Box 32, P.C. 123, Oman. Tel: 968-9989-9847. E-mail aldhafri@squ.edu.om
}

Note: This research received a grant from Sultan Qaboos University (IG/EDU/PSYC/08/01)

Received: August 26, 2019

Accepted: September 19, 2019 Online Published: October 29, 2019

doi:10.5430/jct.v8n4p1

URL: https://doi.org/10.5430/jct.v8n4p1

\begin{abstract}
Students' emotional intelligence represents an important variable that is connected to students' academic achievement and life success. One main challenge when measuring students' emotional intelligence is to have a valid and reliable measure that captures this emotional construct. The current study aims to investigate the psychometric properties of the Arabic version of Alsmadoni emotional intelligence scale (AEIS-25) using item response theory (IRT) models. The study was applied among 3030 students in grades 7-10 in Oman.

Data model fit was examined through evaluating IRT assumptions (i.e. unidimensional assumption and local independence assumption) and goodness of fit (i.e. items fit and persons fit). It was found that item parameters were acceptable and satisfactory, which indicates the appropriateness of AEIS to examine emotional intelligence among adolescents. Findings from exploratory factor analysis for 2924 students and for the remaining 24 items indicated the presence of a 2-factor model since the third factor was loaded by only one item. AEIS was considered as a reliable and potentially valid measure of trait emotional intelligence.
\end{abstract}

Keywords: emotional intelligence, item response theory (IRT), Oman, Arab adolescents

\section{Introduction}

Individuals' capacity to experience a set of reactions and feelings (e.g. happiness, sadness, anger, aggression, love and guilt) in order to add meaning to the communication built between individuals is defined as 'Emotions' (Yee, Yi, Aung, Lwin, \& Myint, 2018). The ability to control the emotions is vital to enhance effective human interaction through avoiding over-exaggeration of reactions toward actions and over-expression of ones' feelings. This capacity to manage and direct emotions has been occurred under the umbrella of 'social intelligence' which is the term that first identified by Thorndike in 1920, and it has been specifically labelled as 'Emotional Intelligence' since 1990 (Wong, Law, \& Wong, 2004). The goal of the current study was to apply Item Response theory (IRT) model to examine the psychometric properties of Alsmadoni Emotional Intelligence Scale (AEIS).

Item response theory (IRT) is a field of Psychometrics that focuses on the measurement and evaluation of psychological or educational latent traits (abilities) such as intelligence or competences levels. In practical terms IRT can be seen a framework for estimating latent traits by means of Observable variables and appropriate statistical Psychometric Models (Magic, Yan, \& Von Davier, 2017). The Graded Response Model (GRM) (Samejima, 1969) was introduced to handle the testing situation where item responses are contained in two or more ordered categories on a rating scale (e.g., Likert scale) (Hambleton \& Swaminathan, 1985).

GRM is considered a generalization of the two- parameter logistic model (2PL), the probability $P^{*}{ }_{i k}(\theta)$ that a person's response falls at or above a particular ordered category given $\Theta$. GRM considers items as a series of K-1 dichotomous items. In which K represent the number of categories in the Likert scale or other ordered category Scale. If a 5 point scale $(0,1,2,3$, and 4$)$, then the following dichotomous are analyzed for each item: 0 vs. 1, 2, 3, 4; 0,1 vs. 2, 3, 4; 0, 1, 2 vs. 3, 4; 0, 1, 2, 3 vs 4 (Zanon, Hutz, Yoo, \& Hambleton, 2016). Samejima (as cited in Hambleton \& 
Swaminathan, 1985) introduce the operating characteristic of a graded response category as

$$
P_{x i}(\theta)=P^{*}{ }_{x i}(\theta)-P_{(x i+1)}(\theta)
$$

$P^{*}{ }_{x_{i}}(\theta)$ : is the regression of the binary item score on latent ability, it represents the probability with which an examinee of ability level receives a score of $x_{i}$.

In general, IRT models common use in recent years is to develop and check psychometric properties of psychological tests, especially graded response model. The use of IRT models should help to advance our understanding of the psychometric properties of the measures used to examine the construct of emotional intelligence. A brief review of emotional intelligence and its measurement follow.

The construction of emotional intelligence has largely been identified and introduced into the psychological literature since the late of twentieth century (e.g. Payne, 1986; Salovey \& Mayer, 1990; Goleman, 1995). Salovey and Mayer (1990), who first proposed the term 'emotional intelligence (EI)' defined it as 'the subset of social intelligence that involves the ability to monitor one's own and others' feelings and emotions, to discriminate among them and use this information to guide one's thinking and actions" (p. 189). The term emotional intelligence has become well-known after Goleman (1995) published his book "Emotional Intelligence: Why it can Matter more than IQ". Goleman (1998) used the term emotional intelligence to refer to a multidimensional concept which indicates to take the possession of four dimensions (social awareness, self-awareness, self-management, and relationship management). However, Davies, Stankov and Roberts (1998) discussed that EI tends to refer to the abilities and they listed three dimensions of EI involving the appraisal of emotion in the self and in others, the regulation of emotion, and the use of emotion. Since 2000, much more evidence on the definition of EI have shown that EI is highly related to the abilities associated with emotions (Mayer, Salovey, \& Caruso, 2000; Mayer, Salovey, Carruso, \& Sitarenios, 2001; Mayer \& Salovey, 2004). It has been emphasized that EI is related to the cognitive competency and it refers to the intellectual ability. A debate has been raised regarding whether EI construct should be assessed as an ability (or skills) or behavioral disposition.

\subsection{EI Measurement: Ability EI Vs. Trait EI}

Researchers have inconsistent findings with regard to the definition of emotional intelligence. Two distinct notions of EI, namely ability EI and Trait EI, have been proposed by Petrides and Furnham (2000). The former is of high relevance to the cognitive ability hierarchies or information-processing abilities while the latter is defined as the "constellation of emotional self-perceptions located at the lower levels of personality hierarchies" (Petrides, Pita, \& Kokkinaki, 2007 as cited in Cooper \& Petrides, 2010, p. 449). These notions play a role to determine the choice of measurement methods used to assess EI. For example, performance tests (e.g. EARS, EISC, MEIS, MSCEIT, \& FNEIPT) are used to assess the ability EI while self-report tests (e.g. EQi, TMMS, SREI, WLEIS, WEIP, \& TEIQue) are the best measure used to assess trait EI (Jonker \& Vosloo, 2008; Lee \& Kwak, 2012).

\subsection{The Positive Outcomes of EI}

An increasing number of studies have found that EI associated positively with overall academic performance (Bar-On, 1997; Hassan, Sulaiman, \& Ishak, 2009; Lopes, Salovey, \& Straus, 2003; Mahyuddin, Elias, \& Noordin, 2009; Nasir \& Masrur, 2010; O’Connor Jr \& Little, 2003; Parker et al., 2004; Rivers et al., 2012; Salami, 2004; Salami \& Ogundokun, 2009; Schutte et al., 1998; Swart, 1996). In addition, studies confirmed connections between emotional intelligence and several psychological positive outcomes such as self-efficacy (Adeyemo \& Adeleye, 2008), social relationship and interaction (Izard et al., 2001, Lopes et al., 2004; Lopes, Salovey, Cote, \& Beers, 2005), social support (Ciarrochi, Chan, \& Bajgar, 2001) and life-satisfaction (Martinez-Pons, 1997; Saklofske, Austin, \& Minski, 2003; Wong et al., 2004). On the other hand, a negative relationship has been found between EI and stress (Pekaar, Bakker, van der Linden, \& Born, 2018), depression (Schutte et al., 1998; Dawda \& Hart, 2000; Saklofske et al., 2003; Hertel, Schutz, \& Lammers, 2009), anxiety (O’Connor Jr \& Little, 2003; Hassan et al., 2009; Rivers et al., 2012) and psychopathology (Schutte, Malouff, Thorsteinsson, Bhullar, \& Rooke, 2007). In the world of work, the higher level of EI among employees is positively associated with work engagement (Xanthopoulou, Bakker, \& Fischbach, 2013; Pekaar et al., 2018), and job satisfaction and lower job burnout (Wong et al., 2004; Brackett, Palomera, Mojsa-Kaja, Reyes, \& Salovey, 2010).

To sum up, all the aforementioned studies have provided a clear indication of the positive outcomes of EI and its role to enhance individuals' overall success of various fields. Since the purpose of the current study is to validate the EI measure and to identify the psychometric properties using exploratory and confirmatory factor analyses, a number of related psychometric studies are examined in following section. 


\subsection{Research on the Psychometric Properties of EI Measure in International Contexts}

A study by Petrides and Furnham (2001) of 227 New Zealand employees working in a transport corporation aimed to examine the psychometric properties of one of the trait EI measures which is the Bar-On Emotional Quotient inventory. This measure included fifteen variables fall in five composites: Interpersonal, Intrapersonal, Adaptability, Stress Management, and General Mood. The researchers validated this instrument based on two studies, Study 1 and Study 2. The result of Study 1 showed that that the five composites were highly correlated so that the measure was found to be a single-factor model including 15 variables representing the global trait EI scale. Additionally, it was found that Emotional Quotient Inventory (EQ-i) fell within the model of Eysenck Personality. However, very low perceived association between trait EI and Psychoticism was found in this study. This was interpreted as there are weak psychometric properties of this particular factor in EPP. In study 2, the researchers used the Five-Factor Model (FFM) to examine the updated or modified EI-i measure along with this model. The sample included 166 students $(85$ undergraduates and 81 postgraduates). The findings showed that trait EI was determined as a distinct lower-ranking construct within FFM.

Another study by Saklofske et al. (2003) sought to validate the trait EI measure designed by Schutte et al. (1998) including 62 items through examining its factor structure. The study sample included 354 university students in Canada, involving 119 male students and 235 female students. After applying an exploratory and confirmatory factor analysis, the findings indicated that within the five EI factors, there were one superordinate factor and four lower-ranking factors in the hierarchical factor structure. So, this study adopted a four-factor model.

Another study by Mikolajczak, Luminet, Leroy and Roy (2007) conducted to examine the psychometric properties of the French version of trait EI questionnaire (TEIQue; Petrides \& Furnham, 2003). The total number of participants was 740 divided into eight samples. Most of the participants were students (484) while the rest were lay individuals (256). A normal distribution of TEIQue scores was found and these scores were also reliable. Moreover, it has been reported that the four-factor model of the UK version of trait EI measure bears a close resemblance to the data of this study.

The psychometric properties of the Farsi version of trait EI scale (FEIS-41) were examined by Besharat (2007). FEIS-41 was administered to 442 undergraduates who were studying at the University of Tehran. The sample comprised of 160 males and 282 females. Besides EIS-41, two other measures were also used in this study. The results showed that the Farsi version of the trait EI measure had an acceptable reliability and validity. It was found that the reliability coefficient value $(\alpha=.89)$ of the Farsi version was higher than the English version of EI scale. However, this value is similar to the original version of EI scale designed by Schutte et al. (1998). In addition, after applying the exploratory factor analysis, it was found that this version is a three-factor model as it supported three factors, namely (1) Regulation of Emotions, (2) Utilization of Emotions, and (3) Appraisal of Emotions.

Jonker and Vosloo's (2008) study of 341 university students (155 males and 169 females) was performed in South Africa to validate the Schutte Emotional intelligence Scale (SEIS-33). The findings obtained from applying a simple factor analysis showed that this scale supported six factors. They can be listed as Positive Affect, Emotion-Others, happy Emotions, Emotions-Own, Non-verbal Emotions and Emotional Management. This result is in contrast with Petrides and Furnham (2000) who found that SEIS supported four factors which are mood regulation, appraisal of emotions, social skills and utilization of emotions. In addition, it has been found that this measure has a good value of internal consistency. The researchers also deleted Item 33 as it had a low score. So, the Schutte Emotional intelligence Scale included 32 items in this study (SEIS-32).

\subsection{Studies Used IRT Model}

Few studies have applied the IRT model to examine the psychometric proprieties of emotional intelligence scales. For Example, Cooper and Petrides (2010) examined the psychometric properties of the Trait Emotional Intelligence Questionnaire-Short Form (TEIQue-SF). The initial sample of Study 1 consisted of 1119 university students, while the total number of participants in Study 2 was 866. The results of Study 1 and 2 were analysed based on the Item Response Theory (IRT). It has been suggested that IRT was effective in analyzing this measure. Furthermore, the results of study 1 showed that the item discrimination and threshold parameters were good. The values of the item information function were high. TEIQue-SF tended also to be precise in measuring the latent traits. Besides, the result of Study 2 confirmed with those obtained from Study 1. Good psychometric properties of the TEIQue-SF were found in this study. Finally, it was suggested that the TEIQue-SF is appropriate to be used to assess the traits of EI.

Two other studies (Pires-Putter \& Jonker, 2013; Van Zyl, 2014) were conducted in South Africa to investigate the psychometric properties of the trait EI measures. Pires-Putter and Jonker's (2013) study focused on examining the Schutte Emotional Intelligence Scale (SEIS) administered to 172 beginner counsellors (21.5\% males and $78.5 \%$ 
females). A simple factor analysis showed two factors named Emotion Appraisal and Emotion Utilization. The Alpha values of these factors were 0.8 and 0.77 respectively. The second study (Van Zyl, 2014) focused on validating the Emotional Quotient Inventory 2.0 (EQ-i-133). The sample was made up of 1144 adult workers and the number of males and females were approximately the same. The results obtained from using Rasch analysis would seem to suggest that the scale items matched the model and the EQ-i had an acceptable reliability.

Cho, Drasgow and Cao (2015) investigated the psychometric properties of three frequently administrated emotional intelligence scale (EL), Wong and Law emotional intelligence Scale (WLEIS), Schutte Self -Report Emotional intelligence Test (SEIT), and trait Emotional Intelligence Questionnaire (TEIQue). The authors examined the item parameters and compared the fits of two models for these scales with data from 355 undergraduate sample by item response theory. The important findings were obtained: EL scale seem better able to differentiate individuals at low trait levels than high, the better model fit to the self- report ability EL scale (WLEIS), and also fit better with most subfactors of the SEIT.

Adriaenssens (2015) Applied item response theory models to investigate the item properties and internal structure of two relatively new tests of emotional intelligence Scale: the situational test of emotional understanding (STEU), and the situational test of emotion management (STEM). Two-parameter logistic model (2PL) shows the best fit with the data. The internal structure test show that violation of unidimesionality assumption. For the STEU data an eight- factor model represent different clusters of emotions, and for the STEM data found four factors solutions.

The psychometric properties of Wong and Law's Emotional Intelligence Scale (WLEIS) was tested by Carvalho, Guerrero, Chambel and González-Rico in 2016. The sample of this study consisted of 481 Spanish students and 473 Portuguese students from two Medicine Colleges. The researchers applied two main measures, one was to measure the trait EI (WLEIS) and the second measure was to assess the engagement variable (UWES-S). WLEIS included 16 items measuring four dimensions which are labelled as Self Emotion Appraisals, Others' Emotion Appraisals, Regulation of Emotion and Emotion Utilization. Significantly, the results of this study emphasized the validity of WLEIS to be used for Spanish and Portuguese students studying at medicine colleges. The findings of both the internal structure analysis and factor analysis verified good matching scale items across the four factors. Another remarkable result to emerge from the data of this study was the positive correlation between WLEIS dimensions and engagement. Taken together, these results suggested good psychometric properties of WLEIS.

Di Fabio, Saklofske and Tremblay's (2016) study of 1154 students (877 high school students and 277 university students) investigated the psychometric properties of TEIQue in Italian context. TEIQue comprised of 153 items measuring fifteen variables and four factors (Well-being, Social-control, Emotionality, and Sociability). Three additional measures were used in this study in order to examine the correlation between the TEIQue scores and these measures. The first measure was the Bar-On Emotional Quotient Inventory (Bar-On EQ-i) which consisted of 133 items measuring five dimensions (Intrapersonal, Interpersonal, Adaptability, Stress management and General mood). The second measure was the Mayer-Salovey-Caruso Emotional Intelligence Test (MSCEIT) which included 143 items and used to assess four factors (Perceiving emotions, Facilitating thought, Understanding emotions, and Managing emotions). The last measure was The Big Five Questionnaire (BFQ) of 132 items used to assess the five common personality traits, namely Extraversion, Agreeableness, Conscientiousness, Emotional Stability and Openness. The findings of the study displayed an excellent reliability of the Italian version of TEIQue $(\alpha=.96)$. The CFA supported the validity of this scale. It has also been found that the correlation between the scores of the Italian version of TEIQue (I- TEIQue) and the scores of the Bar-On EQ-i was significant. However. it was found that there was no significant correlation between the scores of I- TEIQue and MSCEIT. Finally, the correlation between the scores of I- TEIQue and BFQ was described as a positive correlation ranging from low to moderate.

Ulutas (2017) explored the psychometric properties of the Turkish version of the trait EI measure. Five hundred Turkish university students were selected to complete the Trait Emotional Intelligence Questionnaire (TEIQue). This questionnaire included 153 items which measured 15 facets fell within four factors: Well-being, Self-Control, Emotionality, and Sociability. EFA and CFA were applied and the results showed the Turkish version matched appropriately with the original version of TEIQue and it had good psychometric properties. The reliability of the global trait EI was excellent (.90). It has also been found that each factor is highly correlated with the global TEIQue score. To sum up, the Turkish version of TEIQue is a four-factor structure model and it was regarded as a validate instrument that could be used in Turkish context.

One of the most recent studies on this topic conducted by Feher, Yan, Saklofske, Plouffe and Gao (2019). This study investigated the psychometrics of the Chinese version of TEIQue-SF. The study included two samples, Chinese and Canadian samples. About 585 Chinese and 638 Canadian university students participated in this study. The 
questionnaire consisted of 30 items measuring four factors: Well-being, Self-Control, Emotionality, and Sociability. It has been reported that the reliability of TEIQue-SF (of both samples) was good $(\alpha=.88)$ and the correlation between the trait EI factor and global scores of TEIQue-SF was positive. However, the trait EI values ranged from small to large in Chinese sample while they ranged from satisfactory to high in Canadian sample. In addition, the results of the CFA showed that TEIQue-SF of the Chinese version is single-factor structure. It has been acknowledged that the scalar invariance of the two samples failed.

To sum up, the aforementioned international studies have provided a summary of the results obtained in order to investigate the psychometric properties of cross-cultural versions of trait EI measures. Since the number of studies on this topic is too limited in the Arab countries including Oman, the current study aims to examine the psychological properties of the trait EI measure among Omani adolescents (7-10 grade students).

\section{Methodology}

\subsection{The Sample of the Study}

The sample of the current study consisted of 3030 students in the Sultanate of Oman. All the 11 school districts in Oman were involved in the sample. The Technical Office for Research and Development at the Ministry of Education reviewed the study questionnaires and gave ethical approval, which was sent to each school district. Within each school district, some schools were randomly selected based on the population percentage of the total Omani student population. The first author along with a group of research assistants collected data from the participating schools. All invited students agreed to participate in the study. The administration of the questionnaire was during class time with the presence of the class teacher. Students were insured confidentiality and that their participation is voluntary and has no relation with their school work. Informed consent forms were obtained from the participants.

\subsection{The Measure}

The researchers used an Arabic version of the Alsmadoni Emotional Intelligence Scale (AEIS) that was validated by early research (Aldhafri et al., 2011) for the Omani context. The AEIS consists of 25 items that used a 5-point Likert scale. All items are positively worded.

\subsection{The Procedure}

\subsubsection{Examination of Data Model Fit}

The benefit of the use of item response theory (IRT) models is achieved when the mathematical model fits the participants' responses. To examine the model fit, two things need to be evaluated: the evaluation of the mathematical model assumptions on the data and the goodness of fit of the data to the model expectations.

\subsubsection{Examination of Item Response Theory Assumptions}

Parameters estimation accuracy of mathematical item response theory models depend on the existence of these models on the study sample's responses. In this study, the researchers examined the unidimensional assumption and local independence of the Graded Response Model (GRM).

Unidimensional Assumption. The Exploratory factor analysis was used to assess the unidimensional assumption of the measure based on the principal component method of the correlation matrix of the measure 25 items. The result showed the presence of three factors with Eigenvalues greater than one. The total cumulative variance explained by these three factors was $38.25 \%$. The first factor explained $28.47 \%$ of the total variance. The measure is regarded as unifactorial (measuring one construct, namely the emotional intelligence) when the percentage of the first factor explained more than $20 \%$ of variance (Reckase, 1979 as cited in Lee, 2004).

The result of oblique rotation showed that the Eigenvalues of the first three factors were close to each other $(6.05,4.6$, 2.04). So, this may indicate that the measure evaluates one construct only which is the emotional intelligence with the presence of two or three sub-factors correlating different groups of items.

Table 1. Exploratory Factor Analysis

\begin{tabular}{cccc}
\hline Factor & Eigenvalues & \% 0f variance & Eigenvalue(rotation) \\
\hline $\mathbf{1}$ & 6.83 & 28.47 & 6.05 \\
$\mathbf{2}$ & 1.26 & 5.23 & 4.60 \\
$\mathbf{3}$ & 1.09 & 4.55 & 2.04 \\
\hline
\end{tabular}


Local Independent Assumption. The indicator $Q_{3}$ was used to investigate the local independence of items. It estimates the difference between the respondent's observed scores on the measure items and the expected scores of the respondent. Then, the correlation coefficient of these differences of every two items was calculated. The value of $Q_{3}$ ranged between -0.12 and 0.42 which was considered as a high value indicating that there was a local correlation between the items. The results obtained from examining the correlation matrix demonstrated that there was a high correlation between Items 13 and 14. So, it was decided to delete Item 14 since it was less correlated with the total measure score. Thus, the final version of the questionnaire included 24 items.

After that, the items parameters and examinees' abilities were re-estimated through the use of MULTILOG software. The maximum estimated $Q_{3}$ value decreased to 0.16 , which is regarded as an acceptable value, indicating that the local independent assumption between the measure items was achieved.

\subsubsection{Goodness of Fit}

It includes item fit and persons fit:

Items Fit. The idea of the goodness of items fit is based on comparing the expected mathematical model of the respondent's score with the observed response. This could be done either at the level of all items combined or for each individual item. In addition, there are many ways used to assess the items fit such as Chi-square, Likelihood-Ratio Chi-square Test, and Standardized Residuals Index. In this study, the value of the standardized residuals index ranged between 1.28 and 0.90 with a range of 0.38 which is not statistically significant, while Chi-square value ranged between 0.34 and 0.26 with a range of 0.08 . Additionally, the general standardized residuals index of the whole measure (as well as for all items) was 1.11 , and the $p$ value was 0.29 , which is not statistically significant. This result suggested the ability of the Graded Response Model (GRM) to interpret the responses of participants to the measure items.

Table 2. Standardized Residual Index and P Value

\begin{tabular}{cccccc}
\hline item & Index & $\boldsymbol{P}$ & item & Index & $\boldsymbol{P}$ \\
\hline $\mathbf{1}$ & 1.02 & 0.31 & 13 & 1.14 & 1.18 \\
$\mathbf{2}$ & 1.06 & 0.30 & 15 & 1.14 & 0.29 \\
$\mathbf{3}$ & 1.07 & 0.30 & 16 & 1.28 & 0.28 \\
$\mathbf{4}$ & 1.02 & 0.31 & 17 & 1.13 & 0.26 \\
$\mathbf{5}$ & 0.89 & 0.34 & 18 & 1.24 & 0.29 \\
$\mathbf{6}$ & 1.14 & 0.28 & 19 & 1.24 & 0.27 \\
$\mathbf{7}$ & 1.13 & 0.29 & 20 & 1.12 & 0.26 \\
$\mathbf{8}$ & 1.06 & 0.30 & 21 & 1.10 & 0.29 \\
$\mathbf{9}$ & 1.06 & 0.30 & 22 & 1.12 & 0.29 \\
$\mathbf{1 0}$ & 1.04 & 0.31 & 23 & 1.13 & 0.29 \\
$\mathbf{1 1}$ & 1.11 & 0.29 & 25 & 1.18 & 0.29 \\
$\mathbf{1 2}$ & 1.07 & 0.30 & Scale & 1.11 & 0.28 \\
\end{tabular}

Persons Fit. Several indicators are used to examine the persons fit to the model, including Standardized Residuals (Wright \& Masters, 1982), and Likelihood Index (Drasgow, Levine, \& William, 1985). In the current study, the results obtained from the standardized residuals showed that the response patterns of four participants were unfit. Therefore, they were excluded from the study sample. The low mean value $(M=0.31)$ of the error of estimating individuals' abilities emphasizes the accuracy of identifying their level regarding the construct of emotional intelligence.

\section{Results and Discussion}

3.1 Research Question 1: What are the values of item parameter estimates of the Emotional Intelligence Questionnaire and individuals' abilities based on Graded Response Model (GRM) of the Item Response Theory (IRT)?

After assuring the fitness of Graded Response Model (GRM) through examining the unidimensional assumption and local independence of the remaining items (24 items) as well as the items and persons fit, the item parameters estimation (Discriminations and Thresholds) and respondents' abilities were re-estimated through using MULTILOG software. 
Table 3. Items Parameters

\begin{tabular}{|c|c|c|c|c|c|c|}
\hline Item & Discrimination & Threshold1 & Threshold2 & Threshold3 & Threshold4 & Average \\
\hline 1 & 1.37 & -2.18 & -1.45 & -0.19 & 1.32 & 1.37 \\
\hline 2 & 1.00 & -3.07 & -1.65 & 0.19 & 2.18 & 1.00 \\
\hline 3 & 1.17 & -2.92 & -1.77 & -0.38 & 1.18 & 1.17 \\
\hline 4 & 1.15 & -2.67 & -1.87 & -0.85 & 0.50 & 1.15 \\
\hline 5 & 1.68 & -2.10 & -1.47 & -0.63 & 0.49 & 1.68 \\
\hline 6 & 1.07 & -2.66 & -1.29 & 0.32 & 2.13 & 1.07 \\
\hline 7 & 1.19 & -2.95 & -1.79 & -0.14 & 1.65 & 1.19 \\
\hline 8 & 1.51 & -2.59 & -1.61 & -0.69 & 0.69 & 1.51 \\
\hline 9 & 0.99 & -3.08 & -1.91 & -0.37 & 1.31 & 0.99 \\
\hline 10 & 0.98 & -3.23 & -2.17 & -0.72 & 1.07 & 0.98 \\
\hline 11 & 1.11 & -2.80 & -1.55 & 0.06 & 1.71 & 1.11 \\
\hline 12 & 0.98 & -2.88 & -1.52 & 0.12 & 1.85 & 0.98 \\
\hline 13 & 1.24 & -2.68 & -1.60 & -0.32 & 0.99 & 1.24 \\
\hline 15 & 0.35 & -7.55 & -3.61 & 0.08 & 3.72 & 0.35 \\
\hline 16 & 1.13 & -2.36 & -1.32 & -0.06 & 1.45 & 1.13 \\
\hline 17 & 1.39 & -2.37 & -1.46 & -0.45 & 0.89 & 1.39 \\
\hline 18 & 1.05 & -2.89 & -1.91 & -0.65 & 1.09 & 1.05 \\
\hline 19 & 1.15 & -2.81 & -1.65 & -0.26 & 1.30 & 1.15 \\
\hline 20 & 1.26 & -2.75 & -1.84 & -0.65 & 0.88 & 1.26 \\
\hline 21 & 1.11 & -2.79 & -1.61 & -0.14 & 1.41 & 1.11 \\
\hline 22 & 0.95 & -2.99 & -1.70 & 0.07 & 1.93 & 0.95 \\
\hline 23 & 1.15 & -2.94 & -1.68 & -0.23 & 1.52 & 1.15 \\
\hline 24 & 0.98 & -3.22 & -1.79 & -0.15 & 1.60 & 0.98 \\
\hline
\end{tabular}

\subsubsection{Item Parameter Estimation}

The estimation of the discrimination parameters of the Emotional Intelligence Questionnaire items was 1, except for Item $16(0.35)$ and Item $24(0.95)$. This indicates the ability of the questionnaire items to discriminate between the individuals who had higher level of emotional intelligence and those with lower emotional intelligence.

Four thresholds for each item separating the response categories of the five-point Likert scale were also estimated. Through averaging the thresholds of each item, it has been found that Item 17 (I present myself in a way that makes good impression about me) showed the highest threshold which reflects a high level of emotional intelligence. The item that had the lowest threshold was Item 16 (I am aware of other people's non-verbal messages) and it suggests a low level of emotional intelligence. Generally speaking, the results obtained from the estimation of item parameters were acceptable and satisfactory, which seem to show promise as being appropriate to measure the emotional intelligence. This result is very significant when using emotional intelligence in relation to educational and cognitive variables because it helps understand how emotional intelligence can be a significant predictor of these related variables.

\subsubsection{The Estimation of Individuals’ Abilities}

The mean value of estimating the abilities $(M=0.07)$ indicated that the level of emotional intelligence was generally low among the study participants compared to the estimations range $[-4.09,3.10]$. This result was also confirmed by the values of median (0.12) and mode (0.23). Regarding the characteristics of the distribution shape of abilities, the indicators of normality (e.g. the mean and median values were close together, the standard deviation $(S D=0.93)$, Skewness (-0.21), and Kurtosis (0.34)) showed that the scores of participants' abilities tended toward a normal distribution.

3.2 Research Question 2: What are the validity indicators of Emotional Intelligence Questionnaire among university students in the Sultanate of Oman?

\subsubsection{Structure Validity (Factorial validity) Exploratory Factor Analysis (EFA)}

After deleting the item with local correlation and the participants whose responses revealed consistent patterns as well as those who did not fit the model were excluded, EFA was conducted on the remaining 2924 participants and for the remaining 24 items through using principal component analysis while specifying three factors with oblique rotation. 
The results showed that one item loaded on the third factor. Therefore, EFA was re-run with two pre-specified factor model that found to explain $33.8 \%$ of variance.

3.3 Research Question 3: What is the information function of the Emotional Intelligence Questionnaire among university students in the Sultanate of Oman?

The effectiveness of the item on examining the abilities was estimated by the information function which included all item parameters (e.g. discriminations and thresholds) so that the chance to compare between different items and individuals was then possible. The information function is estimated by the following equation:

$$
I\left(\theta, u_{i}\right)=\frac{p_{i}^{2}}{p_{i} q_{i}}
$$

In the two parameters logistic model, the information function is estimated by

$$
I\left(\theta, u_{i}\right)=D^{2} a_{i}^{2} P_{i} Q_{i}
$$

The MULTILOG software is used for the estimation of information function in the ability range $[-3,3]$ and with an increase by 0.2 .

\subsubsection{Test Information Function}

The test information function is produced from a set of item functions which indicates the quality of all items in estimating the construct assessed by the measure. The MULTILOG software is also used to calculate the test information function at ability levels. The results showed that the maximum value of the test information function of the measure was 11.31 at the ability level -1.4, while the lowest value was 7.22 at the ability level 3.00. Additionally, the standard error of estimating the ability estimates was low $(0.26,0.51)$ particularly among those with moderate ability. These results were regarded as a clear evidence of the quality of this measure to assess the construct of emotional intelligence as well as its reliability.

3.4 Research Question 4: What are the reliability indicators of Emotional Intelligence Questionnaire among university students in the Sultanate of Oman?

With regards to the Item Response Theory, the concept of reliability is associated with the item information function $I i(\theta)$, test information function $I T(\theta)$, and standard error of ability estimates (SEE). Thissen (2000) pointed out that the best way to estimate reliability coefficient is through using test information function. He illustrated the relationship between the reliability and test information function according to the following equation:

$$
R_{x x}=1-\frac{1}{\sum_{\mathrm{i}=1}^{\mathrm{n}} \mathrm{I}(\theta)}
$$

$R_{x x}$ indicates the test reliability coefficient while $I(\theta)$ refers to the test information function. This formula emphasizes the positive relationship between the test reliability and test information function.

MULTILOG software is used to estimate the test reliability by relying on this relationship. It has been found that the reliability coefficient of Emotional Intelligence Questionnaire was high (0.90) and this result is in agreement with the value of Cronbach's alpha (0.89) used for estimating the internal consistency reliability of the measure.

3.5 Research Question 5: What are the cut scores used for classifying the categories of Emotional Intelligence Questionnaire among university students in the Sultanate of Oman?

Table 4. Cut Scores for the Categories of Individuals' Ability and Raw Scores in the Emotional Intelligence Questionnaire

\begin{tabular}{ccccc}
\hline Intervals & Ability & Observed & freq & Ratio freq \\
\hline Very low & $\geq-1.5$ & $\geq 36$ & 61 & $12 \%$ \\
Low & $-1.49-0.42$ & $37-59$ & 211 & $41.4 \%$ \\
Moderate & $-0.41-0.65$ & $60-83$ & 181 & $35.5 \%$ \\
High & $0.66-1.73$ & $84-106$ & 52 & $10.2 \%$ \\
Very high & $1.74 \geq$ & $107 \geq$ & 5 & $1 \%$ \\
\hline
\end{tabular}


The data shown in Table 4 present the cut scores and categories which classify the respondents to the emotional intelligence questionnaire into different levels based on either their observed scores or their ability levels. The results showed that $35.5 \%$ of the students had a moderate level of emotional intelligence, and $11.2 \%$ had a high and very high level of emotional intelligence.

\section{Conclusion}

One challenge that faces researchers especially in the Arabic region is to decide in a good measure that can capture the variable under investigation. A common practice found among Arab researchers is the discontinuity of the use of existing measures by researchers across different Arabic countries, even though similarities in language and culture are far beyond possible differences. This practice resulted in the lack of having established measures of psychological constructs (such as emotional intelligence) that can be trusted and further investigated in cumulative informative research efforts.

The current study tried to change this practice by building in early research that used the AEIS by providing a deep investigation of the psychometric properties of the measure using IRT's model. The obtained results provide good understanding of the validity of the measure in examining students' emotional intelligence and deciding on the levels of this construct (based on the adopted curt scores and categories) for possible future comparisons across different samples in Oman and in other Arabic countries. Additional work is needed to examine how this measure functions when applied to different age groups.

\section{Acknowledgment}

The authors would like to thank Sultan Qaboos University (through its fund \# IG/EDU/PSYC/08/01) and The Research Council for providing supportive research facilities for researchers.

\section{References}

Adeyemo, D. A., \& Adeleye, A. T. (2008). Emotional intelligence, religiosity and self-efficacy as predictors of psychological well-being among secondary school adolescents in Ogbomoso, Nigeria. Europe's Journal of Psychology, 4(1). https://doi.org/10.5964/ejop.v4i1.423

Adriaenssens, L. (2015). Item Response Theory Models for Measuring Emotional Intelligence (Master Thesis). Ghent University, Ghent, Belgium.

Aldhafri, S., Kazem, A., Alzubiadi, A., Yousif, Y., Al-Bahrani, M., \& Alkharusi, H. (2011). Parenting styles as perceived by Omani children (classes 7 to 12) and their relationships with some demographic variables. International Journal of Research in Education, 29, 1-26.

Bar-On, R. (1997). Emotional Quotient Inventory: Technical Manual. Toronto: Multi Health Systems.

Besharat, M. A. (2007). Psychometric properties of Farsi version of the Emotional Intelligence Scale-41 (FEIS-41). Personality and individual differences, 43(5), 991-1000. https://doi.org/10.1016/j.paid.2007.02.020

Brackett, M. A., Palomera, R., Mojsa-Kaja, J., Reyes, M. R., \& Salovey, P. (2010). Emotion-regulation ability, burnout, and job satisfaction among British secondary-school teachers. Psychology in the Schools, 47, 406-417. https://doi.org/10.1002/pits.20478

Carvalho, V. S., Guerrero, E., Chambel, M. J., \& González-Rico, P. (2016). Psychometric properties of WLEIS as a measure of emotional intelligence in the Portuguese and Spanish medical students. Evaluation and program planning, 58, 152-159. https://doi.org/10.1016/j.evalprogplan.2016.06.006

Cho, S., Drasgow, F., \& Cao, M. (2015). An investigation of emotional intelligence measures using item response theory. Psychological assessment, 27(4), 12-41. https://doi.org/10.1037/pas0000132

Ciarrochi, J., Chan, A. Y., \& Bajgar, J. (2001). Measuring emotional intelligence in adolescents. Personality and individual differences, 31(7), 1105-1119. https://doi.org/10.1016/S0191-8869(00)00207-5

Cooper, A., \& Petrides, K. V. (2010). A psychometric analysis of the trait emotional intelligence questionnaire-short form (TEIQue-SF) using item response theory. Journal of Personality Assessment, 92(5), 449-457. https://doi.org/10.1080/00223891.2010.497426

Davies, M., Stankov, L., \& Roberts, R. D. (1998). Emotional intelligence: In search of an elusive construct. Journal of personality and social psychology, 75(4), 989. https://doi.org/10.1037/0022-3514.75.4.989 
Dawda, D., \& Hart, S. D. (2000). Assessing emotional intelligence: reliability and validity of the Bar-On Emotional Quotient Inventory (EQ-i) in university students. Personality and Individual Differences, $28,797-812$. https://doi.org/10.1016/S0191-8869(99)00139-7

Di Fabio, A., Saklofske, D. H., \& Tremblay, P. F. (2016). Psychometric properties of the Italian trait emotional intelligence questionnaire (I-TEIQue). Personality and Individual Differences, 96, 198-201. https://doi.org/10.1016/j.paid.2016.03.009

Drasgow, F., Levine, M. V., \& Williams, E. A. (1985). Appropriateness measurement with polytomous item response models and standardized indices. British Journal of Mathematical and statistical psychology, 38, 67-86. https://doi.org/10.1111/j.2044-8317.1985.tb00817.x

Feher, A., Yan, G., Saklofske, D. H., Plouffe, R. A., \& Gao, Y. (2019). An Investigation of the psychometric properties of the Chinese Trait Emotional Intelligence Questionnaire Short Form (Chinese TEIQue-SF). Frontiers in Psychology, 10, 435. https://doi.org/10.3389/fpsyg.2019.00435

Goleman, D. (1995). Emotional intelligence. New York: Bantam Books.

Goleman, D. (1998). Working with emotional intelligence. Bantam Books: New York. https://doi.org/10.1002/ltl.40619981008

Hambleton, R., \& Swaminathan, H. (1985). Item Response Theory: Principles and applications. Boston. MA: Kluwer-Nijhoff. https://doi.org/10.1007/978-94-017-1988-9

Hassan, A., Sulaiman, T., \& Ishak, R. (2009). Philosophy underlying emotional intelligence in relation to level of curiosity and academic achievement of rural area students. Journal of Social Sciences (15493652), 5(2), 95-103. http://dx.doi.org/10.3844/jssp.2009.95.103

Hertel, J., Schutz, A., \& Lammers, C. H. (2009). Emotional intelligence and mental disorder. Journal of Clinical Psychology, 65, 942-954. https://doi.org/10.1002/jclp.20597

Izard, C. E., Fine, S., Schultz, D., Mostow, A. J., Ackerman, B., \& Youngstrom, E. (2001). Emotion knowledge as a predictor of social behavior and academic competence in children at risk. Psychological Science, 12, 18-23. https://doi.org/10.1111/1467-9280.00304

Jonker, C. S., \& Vosloo, C. (2008). The psychometric properties of the Schutte emotional intelligence scale. SA Journal of Industrial Psychology, 34(2), 21-30. https://doi.org/10.4102/sajip.v34i2.689

Khin Than Yee, Myat San Yi, Khin Cho Aung, Mar Mar Lwin \& Wai Wai Myint. (2018). Emotional intelligence level of year one and two medical students of University Malaysia Sarawak: Association with demographic data. Malaysian Applied Biology, 47(1), 203-208.

Lee, H., \& Kwak, Y. (2012). Development and initial validation of a trait emotional intelligence scale for Korean adults. Asia Pacific Education Review, 13(2), 209-217. https://doi.org/10.1007/s12564-011-9175-8

Lee, Y. (2004). Examining passage-related local item dependence (LID) and measurement construct using Q3 statistics in an EFL reading comprehension test. Language testing, 21(1), 74-100. https://doi.org/10.1191/0265532204lt260oa

Lopes, P. N., Brackett, M. A., Nezlek, J. B., Schutz, A., Sellin, I., \& Salovey, P. (2004). Emotional intelligence and social interaction. Personality and Social Psychology Bulletin, 30, 1018-1034. https://doi.org/10.1177/0146167204264762

Lopes, P. N., Salovey, P., \& Straus, R. (2003). Emotional intelligence, personality, and the perceived quality of social relationships. Personality and Individual Differences, https://doi.org/10.1016/S0191-8869(02)00242-8

Lopes, P. N., Salovey, P., Cote, S., \& Beers, M. (2005). Emotion regulation abilities and the quality of social interaction. Emotion, 5, 113-118. https://doi.org/10.1037/1528-3542.5.1.113

Magic, D., Yan, D., \& Von Davier, A. (2017). Computerized Adaptive and multistage testing with R. New York: Springer. https://doi.org/10.1007/978-3-319-69218-0

Mahyuddin, R., Elias, H., \& Noordin, N. (2009). Emotional intelligence, achievement motivation and academic achievement among students of the public and private higher institutions. International Journal of Diversity in Organisations, Communities \& Nations, 9(4), 135-144. https://doi.org/10.18848/1447-9532/CGP/v09i04/39742

Martinez-Pons, M. (1997). The relation of emotional intelligence with selected areas of personal functioning. 
Imagination, Cognition and Personality, 17, 3-13. https://doi.org/10.2190/68VD-DFXB-K5AW-PQAY

Mayer, J. D., \& Salovey, P. (2004). What is emotional intelligence? In Salovey P, Brackett MA and Mayer JD (eds.), Emotional Intelligence: Key Readings on the Mayer and Salovey model. Port Chester: Dude Publishing, pp. 29-59.

Mayer, J. D., Salovey, P. R., \& Caruso, D. R. (2000). Emotional intelligence as Zeitgeist, as personality, and as a mental ability. In R. Bar-On \& J. D. A. Parker (Eds.), The handbook of emotional intelligence (pp. 92-117). San Francisco: Jossey-Bass.

Mayer, J. D., Salovey, P., Carruso, D. R \& Sitarenios, G. (2001). Emotional intelligence as a standard Intelligence. Emotion. 1, 232-242. https://doi.org/10.1037/1528-3542.1.3.232

Mikolajczak, M., Luminet, O., Leroy, C., \& Roy, E. (2007). Psychometric properties of the Trait Emotional Intelligence Questionnaire: Factor structure, reliability, construct, and incremental validity in a French-speaking population. Journal of personality assessment, 88(3), 338-353. https://doi.org/10.1080/00223890701333431

Nasir, M., \& Masrur, R. (2010). An exploration of emotional intelligence of the students of IIUI in relation to gender, age and academic achievement. Bulletin of Education \& Research, 32(1), 37-51.

O’Connor Jr, R., \& Little, I. (2003). Revisiting the predictive validity of emotional intelligence: Selfreport versus ability-based measures. Personality and Individual Differences, 35, 1893-1902. https://doi.org/10.1016/S0191-8869(03)00038-2

Parker, J. D., Creque Sr, R. E., Barnhart, D. L., Harris, J. I., Majeski, S. A., Wood, L. M., ... \& Hogan, M. J. (2004). Academic achievement in high school: does emotional intelligence matter? Personality and individual differences, 37(7), 1321-1330. https://doi.org/10.1016/j.paid.2004.01.002

Payne, W. L. (1986). A Study of Emotion: Developing Emotional Intelligence; Self-Integration: Relating to Fear, Pain, and Desire. Doctoral Dissertation at the Union Graduate School. Cincinnati, OH. [Original dissertation work submitted and accepted, May, 1983].

Pekaar, K. A., Bakker, A. B., van der Linden, D., \& Born, M. P. (2018). Self-and other-focused emotional intelligence: Development and validation of the Rotterdam Emotional Intelligence Scale (REIS). Personality and Individual Differences, 120, 222-233. https://doi.org/10.1016/j.paid.2017.08.045

Petrides, K. V., \& Furnham, A. (2000). On the dimensional structure of emotional intelligence. Personality and individual differences, 29(2), 313-320. https://doi.org/10.1016/S0191-8869(99)00195-6

Petrides, K. V., \& Furnham, A. (2001). Trait emotional intelligence: psychometric investigation with reference to established trait taxonomies. European Journal of Personality, 15(6), 425-448. https://doi.org/10.1002/per.416

Petrides, K. V., \& Furnham, A. (2003). Trait emotional intelligence: Behavioral validation in two studies of emotion recognition and reactivity to mood induction. European Journal of Personality, 17, 29-57. https://doi.org/10.1002/per.466

Petrides, K. V., Pita, R., \& Kokkinaki, F. (2007). The location of trait emotional intelligence in personality factor space. British Journal of Psychology, 98, 273-289. https://doi.org/10.1348/000712606X120618

Pires-Putter, J. K., \& Jonker, C. S. (2013). The psychometric properties of an emotional intelligence measure within non-professional counsellors in South Africa. Journal of Psychology in Africa, 23(4), 585-588. https://doi.org/10.1080/14330237.2013.10820671

Reckase, M. D. (1979). Unifactor latent trait models applied to multifactor tests: results and implications. Journal of Educational Statistics, 4, 207-30. https://doi.org/10.3102/10769986004003207

Rivers, S. E., Brackett, M. A., Reyes, M. R., Mayer, J. D., Caruso, D. R., \& Salovey, P. (2012). Measuring emotional intelligence in early adolescence with the MSCEIT-YV: Psychometric properties and relationship with academic performance and psychosocial functioning. Journal of Psychoeducational Assessment, 30(4), 344-366. https://doi.org/10.1177/0734282912449443

Saklofske, D. H., Austin, E. J., \& Minski, P. S. (2003). Factor structure and validity of a trait emotional intelligence $\begin{array}{llll}\text { measure. Personality and Individual } & \text { differences, }\end{array}$ https://doi.org/10.1016/S0191-8869(02)00056-9

Salami, S.O. \& Ogundokun, M.O. (2009). Emotional intelligence and self-efficacy as predictors of academic performance. Perspectives in Education, 25(3), 175-185. 
Salami, S.O. (2004). Affective characteristics as of determinants of academic performance of school-going adolescents: Implication for counselling and practice. Sokoto Educational Review, 7, 145-160.

Salovey, P., \& Mayer, J. D. (1990). Emotional intelligence. Imagination, cognition and personality, 9(3), 185-211. https://doi.org/10.2190/DUGG-P24E-52WK-6CDG

Samejima, F. (1969). Estimation of latent ability using a response pattern of graded scores. Psychometrika Monograph Supplement, 34(4, Pt. 2), 100. https://doi.org/10.1007/BF03372160

Schutte, N. S., Malouff, J. M., Hall, L. E., Haggerty, D. J., Cooper, J. T., \& Golden, C. J. (1998). Development and validation of a measure of emotional intelligence. Personality and Individual Differences, 25, 167-177. https://doi.org/10.1016/S0191-8869(98)00001-4

Schutte, N. S., Malouff, J. M., Thorsteinsson, E. B., Bhullar, N., \& Rooke, S. E. (2007). A meta-analytic investigation of the relationship between emotional intelligence and health. Personality and Individual Differences, 42, 921-933. https://doi.org/10.1016/j.paid.2006.09.003

Swart, A. (1996). The relationship between well-being and academic performance. (Unpublished Master's Thesis), University of Pretoria, South Africa.

Thissen, D. (2000). Reliability and measurement precision. In H. Wainer (Ed.), Computerized adaptive testing: A primer (pp. 159-184). Mahwah, NJ, US: Lawrence Erlbaum Associates Publishers.

Thorndike, E. L. (1920). Intelligence and its uses. Harper's Magazine, 140, 227-235.

Ulutas, I. (2017). Psychometric Properties of the Trait Emotional Intelligence Questionnaire (TEIQe) in Turkish. Current Psychology, 38(3), 775-781. https://doi.org/10.1007/s12144-017-9647-z

Van Zyl, C. J. (2014). The psychometric properties of the emotional quotient inventory 2.0 in South Africa. SA Journal of Industrial Psychology, 40(1), 1-8. https://doi.org/10.4102/sajip.v40i1.1192

Wong, C. S., Law, K. S., \& Wong, P. M. (2004). Development and validation of a forced choice emotional intelligence measure for Chinese respondents in Hong Kong. Asia Pacific Journal of Management, 21(4), 535-559. https://doi.org/10.1023/B:APJM.0000048717.31261.d0

Wright, B. D., \& Masters, G. N. (1982). Rating scale analysis: Rasch measurement. Chicago: Mesa Press.

Xanthopoulou, D., Bakker, A. B., \& Fischbach, A. (2013). Work engagement among employees facing emotional demands. Journal of Personnel Psychology, 12, 74-84. Retrieved from https://doi.org/10.1027/1866-5888/a000085.

Zanon, C., Hutez, C., Yoo, H., \& Hambleton, R. (2016). An application of item response theory to Psychological test development. Psiclogia: Reflaxia e critica, 29(1), 1-10. https://doi.org/10.1186/s41155-016-0040-x 